(c) American Dairy Science Association, 2006.

\title{
Flooring in Front of the Feed Bunk Affects Feeding Behavior and Use of Freestalls by Dairy Cows
}

\author{
C. B. Tucker, ${ }^{* 1}$ D. M. Weary, ${ }^{*}$ A. M. de Passillé, ${ }^{*} \dagger$ B. Campbell, ${ }^{*}$ and J. Rushen ${ }^{\star} \dagger$ \\ *Animal Welfare Program, University of British Columbia, Vancouver, BC, Canada V6T $1 Z 4$ \\ †Pacific Agri-Food Research Centre, Agriculture and Agri-Food Canada, Agassiz, BC, Canada V0M 1A0
}

\begin{abstract}
In 2 experiments we assessed how preferences, time budgets, and feeding behavior of dairy cows change in response to flooring surfaces in front of the feed bunk. In Experiment 1, 12 nonlactating dairy cattle were individually housed with access to 2 standing platforms filled with either concrete or sawdust. In Experiment 2, 24 nonlactating dairy cattle were given access to either concrete or Animat rubber flooring in front of the feed bunk. In Experiment 1, cows preferred the sawdust to the concrete flooring. In both experiments, cows provided with a softer floor in front of the feed bunk spent more time standing near the feed bunk without eating (Experiment 1: $67 \mathrm{vs.} 40 \mathrm{~min} / \mathrm{d}$ on sawdust vs. concrete, respectively, $\mathrm{SEM}=5.6 \mathrm{~min} / \mathrm{d}$; Experiment 2: 176 vs. $115 \mathrm{~min} / \mathrm{d}$ on Animat vs. concrete, respectively, $\mathrm{SEM}=20.5 \mathrm{~min} / \mathrm{d}$ ) compared with when they were kept on concrete. The increased time spent at the feed bunk was due to a combination of more frequent eating and standing bouts, indicating that cows were more willing to move on nonconcrete flooring. Total time spent eating was significantly greater on the softer floor in Experiment 2, but not in Experiment 1 (Exp. 1: 289 vs. $275 \mathrm{~min} / \mathrm{d}$ on sawdust and concrete, respectively, $\mathrm{SEM}=7.3 \mathrm{~min} / \mathrm{d}$; Exp. 2: 330 vs. $289 \mathrm{~min} /$ $\mathrm{d}$ on Animat and concrete, respectively, SEM = 15.4), although feed intake was increased on the sawdust treatment in Experiment 1. Cows spent significantly more time lying in the feed alley when the flooring was rubber (219 vs. $53 \mathrm{~min} / \mathrm{d}$ on Animat and concrete, $\mathrm{SEM}=53.6 \mathrm{~min} / \mathrm{d}$ ), perhaps because the lying area in Experiment 2 was inadequate. In conclusion, cows prefer to stand on softer flooring in front of the feed bunk, and are more willing to move on and spend more time standing in front of the feed bunk when provided with softer flooring. These results indicate that cows find softer flooring surfaces more comfortable to stand
\end{abstract}

Received October 17, 2005.

Accepted January 4, 2006.

${ }^{1}$ Corresponding author: cassandra.tucker@agresearch.co.nz on than concrete, and highlight the importance of evaluating the comfort of the entire facility.

Key words: welfare, preference, cow comfort, cubicle

\section{INTRODUCTION}

Intensively housed dairy cattle spend most of their time indoors and the design of their housing can affect both health and behavior. Most research on cow comfort has focused on stall design, but for cows housed in freestalls, the flooring surfaces outside the stall may also be important. Dairy cows in North America are increasingly housed on concrete floors (USDA, 2002), and this flooring surface has been associated with an increased incidence of lameness and hoof problems (e.g., Vokey et al., 2001; Cook, 2003; Somers et al., 2003).

In addition to influencing hoof health, concrete flooring can impair locomotion (Jungbluth et al., 2003; Rushen et al., 2004; van der Tol et al., 2005), influence expression of estrus behavior (Phillips and Schofield, 1994; Lopez and Shipka, 2003), and grooming (Jungbluth et al., 2003). Cattle show distinct preferences for softer flooring for lying and standing (Lowe et al., 2001; Manninen et al., 2002; Tucker and Weary, 2004) and choose floors with more traction when walking (Phillips and Morris, 2001).

For these reasons, there is increasing interest in alternative flooring materials for dairy barns, especially floors that have better friction and are softer than concrete. Given that cattle spend 4 to $6 \mathrm{~h} / \mathrm{d}$ eating in freestall barns, replacing the concrete flooring in front of feed bunks may be especially beneficial. Few studies, however, have examined the advantages of providing softer floors in front of feed bunks. Fregonesi et al. (2004) found that dairy cows spent more time standing near the feed bunk when on a rubber surface compared with concrete, but there were no effects on feeding time. In addition, the cows spent more time standing elsewhere in the pen even though this was concrete flooring. However, they examined cows in groups, and competition within groups may have masked the effects of rubber flooring.

In this study, we examined individually housed cows to more precisely assess the effects of the flooring sur- 
faces in front of the feed bunk on feeding and resting behavior. The objectives were 2-fold: 1) to assess whether dairy cattle prefer softer flooring surfaces in front of the feed bunk, and 2) to understand how softer flooring surfaces in front of the feeding area affect the resting, standing, and feeding behavior of dairy cattle. In the first experiment we tested a surface much softer than concrete (sawdust), and in the second experiment we tested a commercially available flooring material, Animat.

\section{MATERIALS AND METHODS}

\section{Experiment 1}

In this experiment, we examined preferences of cows for softer flooring in front of the feed bunks and how the softness of the flooring affected feeding and resting time and feed intake. We used 12 pregnant, nonlactating Holstein dairy cattle $[\mathrm{BW}($ mean $\pm \mathrm{SE})=759 \pm 24.0$ $\mathrm{kg}$, range $=588$ to $881 \mathrm{~kg}$; stage of pregnancy $=34 \pm$ $0.7 \mathrm{wk}$, range: 29 to $36 \mathrm{wk}$. Cows were individually housed in 1 of 3 similar test pens in a freestall flush barn (3\% slope) with automatic waterers. Each cow had access to 4 freestalls $(114 \mathrm{~cm}$ wide $\times 234 \mathrm{~cm}$ long with an 20-cm concrete curb) deep-bedded with $20 \mathrm{~cm}$ of green hemlock sawdust, and 1 stall $(114 \mathrm{~cm} \times 233 \mathrm{~cm}$ with a $20 \mathrm{~cm}$ concrete curb) bedded with a PastureMat (Promat Ltd., Seaforth, Ontario, Canada) mattress covered in 3 to $5 \mathrm{~cm}$ of green hemlock shavings. The stalls did not contain neck rails or brisket boards. Stalls were cleaned and leveled twice daily and the barn was flushed each morning. Barn lights were on between 0730 and $2200 \mathrm{~h}$. In addition, to facilitate video recording, 100-W red lights were used above the feed bunk and freestalls at all times.

In front of the feeding area of each pen were 2 platforms that cows stood upon to gain access to the feed bunk. Platforms were built of $15 \mathrm{~cm} \times 15 \mathrm{~cm}$ lumber, measured $91 \mathrm{~cm} \times 183 \mathrm{~cm}$, and were set $26 \mathrm{~cm}$ apart from each other. One platform was filled with poured, ungrooved concrete and the other with green hemlock sawdust. The sawdust treatment was chosen to provide a much softer alternative to the concrete. The flooring treatments varied in depth across the width of the platform correcting the $3 \%$ slope in the floor of the pen to achieve a level standing surface. The relative position (left or right) of the 2 platforms along the side of the feed bunk space was randomly allocated and balanced across pens. Plywood dividers $(53 \mathrm{~cm} \times 122 \mathrm{~cm})$ separated the feeding platforms and prevented cows from eating from 1 feeder while standing on the surface in front of the other feeder. Headlocks separated the feed from the flooring surfaces. Cows had ad libitum access to hay (88\% DM), with fresh feed provided at $0900 \mathrm{~h}$ and remaining feed removed and weighed.

Cows were allowed $1 \mathrm{wk}$ to adjust to the flooring treatments. The experiment was divided into 2 phases. In the first or restriction phase, cows were allowed access to only 1 treatment at a time for $4 \mathrm{~d}$. Order of access was determined randomly and balanced across cows. To ensure that cows only used 1 treatment during the restriction phase, hay was only offered in front of the allocated platform and sawdust was removed from the flooring platform during the concrete treatment. In the second or preference phase, hay was offered in front of both platforms for a period of $3 \mathrm{~d}$. Three cows were tested simultaneously, in 3 separate test pens, for 4 repetitions providing a total of 12 subjects.

Cow behavior on the feeding platforms and freestalls was videotaped continuously using 2 video cameras per pen, recording $72 \mathrm{~h}$ on a 6 -h tape. The recordings were watched continuously by 3 observers, with each cow observed by only 1 person. The behavior of the cows' was scored as either lying or standing and the position of the cow in the pen was noted. Each pen was divided into 3 parts: feeding area (including the area in front of the feed bunk, either with sawdust or concrete platform); alleyway (which was the solid concrete area between the feeding area and the freestalls); and the freestalls. Standing behavior in the feeding area was divided into standing with the head in the feeder ("eating") or not ("standing not eating"). Standing in the stall was divided into standing with either 3 or 4 legs in the stall or with only the 2 front legs in the stall. We recorded the number of times the cow entered the stall with at least the front hooves. Lying down outside the stall was rarely seen and was not formally recorded. During the preference phase, we recorded time spent with the head in ("eating") and out of the feeder ("standing without eating"), position of front and hind legs on the feeding platform from the video tapes, as well as feed intake.

Statistical Analyses. Both duration and frequency of the behaviors were recorded; however, only total duration of time spent standing in the alleyway was measured. To test the effect of flooring surface during the restriction phase, each cow served as the observational unit, because each cow was tested in each treatment. Values from the 4-d observation period on each surface were averaged. The distributions of many measures were positively skewed and transformations were not able to correct for this, so all behavioral data were ranked before analyses (Conover and Iman, 1981). All measures taken during the restriction phase were analyzed using a GLM (SAS Institute, 1999). The GLM included terms for cows (11 df), order of restriction (1 $\mathrm{df}$ ), and tested the effect of treatment (concrete vs. saw- 
dust, $1 \mathrm{df}$ ) against the residual term (10 df). In the preference phase of the experiment, data were averaged across the 3-d collection period and analyzed using the Wilcoxon signed-rank test comparing the percentage of time or hay consumed on the sawdust surface against the expected $50 \%$. Preference for flooring treatment was based on the percentage time spent eating, standing without eating, total standing time, and the percentage of hay eaten from the feeding platform with sawdust flooring.

Information from 3 cows during the restriction phase ( 1 cow for $5 \mathrm{~d}$ and 2 cows for $1 \mathrm{~d}$ each) and $1 \mathrm{~d}$ from 1 cow in the preference phase were excluded from the data set because of failure of the video equipment.

\section{Experiment 2}

In this experiment, we tested a rubber flooring material (Animat, Animat Inc., Saint-Élie d'Orford, QC, Canada) that is used in some commercial dairies. We used 16 pregnant multiparous cows and 8 pregnant nulliparous cows [BW (mean $\pm \mathrm{SE})=704 \pm 19.0 \mathrm{~kg}$, range $=544$ to $942 \mathrm{~kg}$; stage of pregnancy $=32 \pm 0.5$ wk, range $=24$ to $33 \mathrm{wk}$. Cows were housed in individual pens, with 2 lying stalls $(114 \mathrm{~cm}$ wide $\times 216 \mathrm{~cm}$ long) covered with a hard rubber mat. At the opposite end of the pen from the stalls was a 2.43-m feed bunk. A single nipple drinker was placed above the feed bunk. The floor in front of the feed bunk $(2.43 \mathrm{~m}$ width $\times 1.57$ $\mathrm{m}$ depth) consisted of concrete slats (slats were $16.5 \mathrm{~cm}$ wide and slots measured $3.8 \mathrm{~cm}$ ). The alleyway between this slatted floor and the lying stalls was solid, ungrooved concrete. Cows were fed grass silage and chopped hay at $1040 \mathrm{~h}$ each day.

All pens were in a single barn with 2 rows of pens separated by an alleyway. For half of the pens (Animat), the entire area of the concrete slatted floor in front of the feed bunk was covered with Animat cut to cover the slats but leave the gaps between slats open. For the other half of the pens (concrete), the slats were left as they were. The 2 types of pens were alternated throughout the barns such that pens opposite from each other had different types of flooring. The compressibility of Animat $\left(70 \mathrm{~N} / \mathrm{cm}^{2}\right)$ is 3.2 times greater than that of concrete and the coefficient of friction for Animat is greater than for concrete for both static and dynamic measures (1.4 and 1.3 times greater, respectively; M. Comeau, Centre de recherche industrielle du Québec, Ste-Foy, QC, Canada, personal communication).

Cows were randomly assigned to pens with either Animat or concrete flooring, with equal numbers of multiparous or nulliparous cows in each. Cows were observed for $2 \mathrm{wk}$ on each material. Before observations began, the cows were placed in the pens for a 2 -wk adaptation period. After the first observation period, cows were switched to the alternative flooring treatment by being moved to the opposite pen. The cows remained in the new pens for a 1-wk adaptation period before the second 2-wk observation period began. Thus, each cow was exposed to both treatments, with the order of treatments balanced across animals.

Each pen was filmed using a single video camera per pen. Six cameras were connected to a multiplexer, which recorded $48 \mathrm{~h}$ on a 2 -h tape. Twenty-four hour recordings were made on $d 8,11$, and 14 of each 2 wk observation period. The recordings were watched continuously by 2 observers, with each cow observed by only 1 person. The behavior of the cows was scored as either lying or standing, and the position of the cow in the pen was noted. Each pen was divided into 3 parts: feeding area (including the slatted area in front of the feed bunk, covered in either concrete or Animat); alleyway (which was the solid concrete area between the feeding area and the freestalls); and the freestalls. Standing behavior in the feeding area was divided into standing with the head in the feeder ("eating") or not ("standing not eating"). Each use of the drinker nipple was recorded. Standing in the stall was divided into standing with either 3 or 4 legs in the stall or with only the 2 front legs in the stall.

Statistical Analyses. For each behavior except drinking we calculated the total duration and frequency of bouts in each part of the barn. For drinking we only recorded the frequency of drinker usage, as the short duration of this behavior made it difficult to accurately record duration using our sampling methods. The distributions of all measures were positively skewed (except for time spent lying in the freestall, which was bimodally distributed) and transformations did not correct for this. Thus, all data were ranked for analyses. Repeated measures ANOVA were run on ranked data using a mixed model (SAS Institute, 1999). Factors examined were cow (22 df), type of floor (Animat vs. concrete; $1 \mathrm{df}$ ), parity ( $1 \mathrm{df})$, day ( $2 \mathrm{df}$ ), and interactions between type of floor and day and parity ( $2 \mathrm{df})$. The effect of flooring type was tested against an error term ( $21 \mathrm{df})$. The results of 1 nulliparous cow were lost because of a failure of the video equipment.

\section{RESULTS}

\section{Experiment 1}

In the preference phase of the experiment, when the cows were given a choice between the 2 materials, they spent more time eating, standing without eating, and more total time on the sawdust surface than on concrete (Figure $1 ; P<0.01$ ). The cows also consumed more hay 


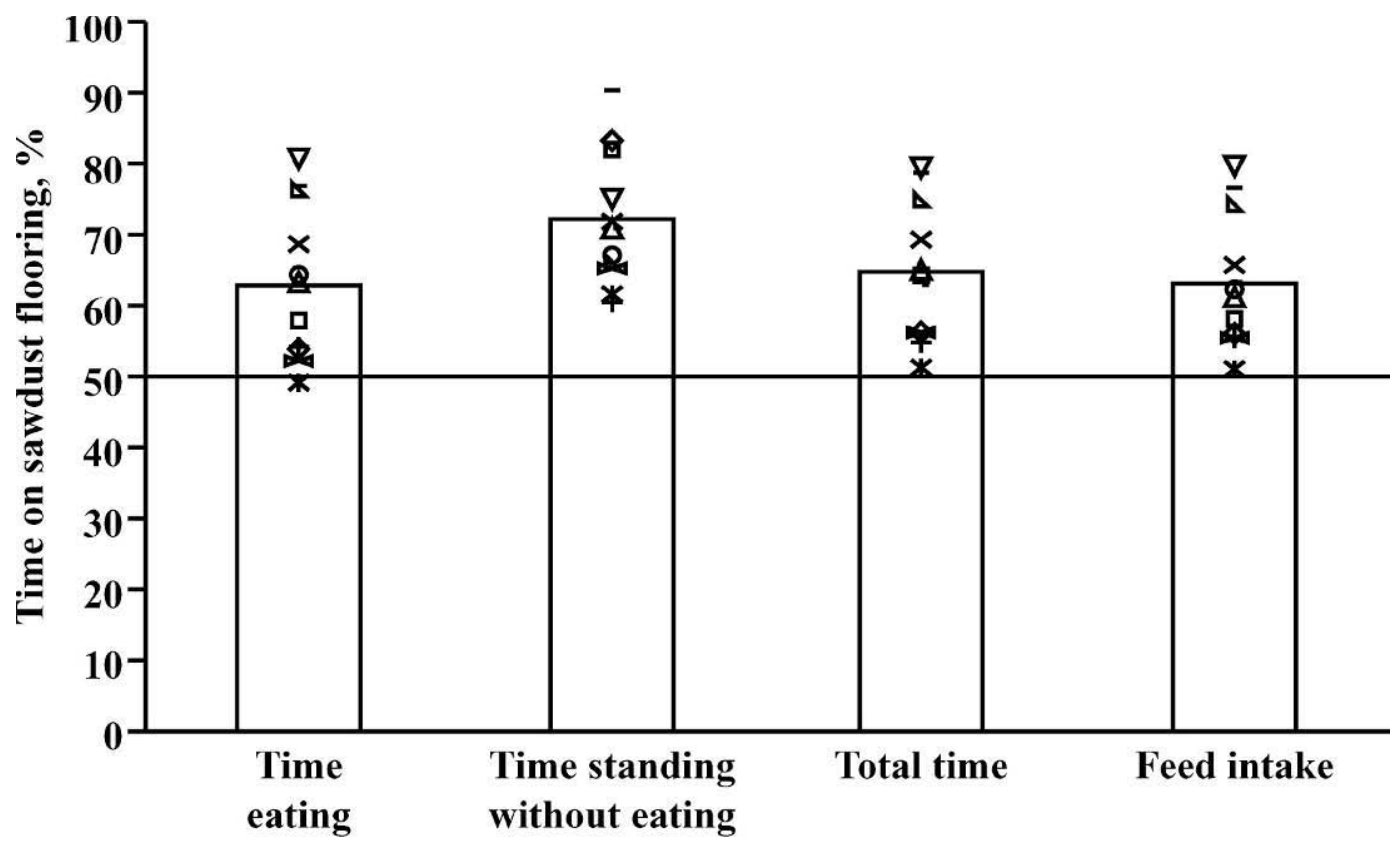

\section{Measure of preference}

Figure 1. Scatter plots showing preference for sawdust flooring surface compared with concrete flooring in front of the feed bunks based on percentage time spent eating, standing without eating, total time, and feed intake in Experiment 1 . Different symbols represent the values of the 12 individual cows, and the bars represent the mean value for each measure.

from feeder in front of the sawdust flooring when given a choice between treatments $(P<0.01)$.

When restricted to each material in turn, cows consumed $800 \mathrm{~g} / \mathrm{d}$ more on the sawdust surface than concrete (sawdust vs. concrete: $15.5 \pm 0.25$ vs. $14.7 \pm 0.25$ $\mathrm{kg} / \mathrm{d} ; P<0.05)$. There was no difference in total time spent eating on the 2 surfaces (Table 1 ), but there were differences in the postures adopted by the cows while eating. Cows spent an additional $69 \mathrm{~min} / \mathrm{d}$ eating with all 4 legs on the sawdust surface, due to more frequent

Table 1. Mean ( \pm SEM) total frequency and duration of behaviors of cows with either concrete or sawdust installed in front of the feed bunk in Experiment $1(\mathrm{n}=12)$

\begin{tabular}{|c|c|c|c|c|c|c|}
\hline & \multicolumn{3}{|c|}{ Bout frequency (no./24 h) } & \multicolumn{3}{|c|}{ Total duration $(\mathrm{min} / 24 \mathrm{~h})$} \\
\hline & Concrete & Sawdust & $P$ & Concrete & Sawdust & $P$ \\
\hline $\begin{array}{l}\text { Total standing } \\
4 \text { legs in feeding area }\end{array}$ & $10.7 \pm 0.3$ & $10.3 \pm 0.3$ & 0.86 & $682 \pm 7.2$ & $699 \pm 7.2$ & 0.13 \\
\hline Eating & $19.8 \pm 2.4$ & $27.1 \pm 2.4$ & 0.05 & $226 \pm 13.9$ & $285 \pm 13.9$ & $<0.01$ \\
\hline Without eating & $1.4 \pm 0.5$ & $4.1 \pm 0.5$ & $<0.01$ & $1 \pm 1.3$ & $7 \pm 1.3$ & $<0.01$ \\
\hline Total & $21.1 \pm 2.5$ & $31.2 \pm 2.5$ & 0.01 & $227 \pm 14.2$ & $292 \pm 14.2$ & $<0.01$ \\
\hline \multicolumn{7}{|l|}{2 legs in feeding area } \\
\hline Eating & $5.7 \pm 0.8$ & $1.4 \pm 0.8$ & $<0.01$ & $49 \pm 13.7$ & $4 \pm 13.7$ & $<0.01$ \\
\hline Without eating & $26.1 \pm 2.0$ & $30.5 \pm 2.0$ & 0.30 & $39 \pm 5.3$ & $60 \pm 5.3$ & $<0.01$ \\
\hline Total & $31.9 \pm 2.0$ & $32.0 \pm 2.0$ & 0.94 & $89 \pm 16.4$ & $64 \pm 16.4$ & 0.55 \\
\hline \multicolumn{7}{|l|}{ Total in feeding area } \\
\hline Eating & $25.5 \pm 1.9$ & $28.5 \pm 1.9$ & 0.20 & $275 \pm 7.3$ & $289 \pm 7.3$ & 0.23 \\
\hline Without eating & $27.5 \pm 1.9$ & $34.6 \pm 1.9$ & 0.02 & $40 \pm 5.6$ & $67 \pm 5.6$ & $<0.01$ \\
\hline Total visits & $11.7 \pm 0.7$ & $11.9 \pm 0.7$ & 0.66 & $315 \pm 9.6$ & $356 \pm 9.6$ & 0.01 \\
\hline Standing in alleyways & - & - & - & $267 \pm 12.8$ & $230 \pm 12.8$ & 0.12 \\
\hline \multicolumn{7}{|l|}{ Standing in freestalls } \\
\hline With front legs in stall & $11.7 \pm 0.8$ & $12.7 \pm 0.8$ & 0.77 & $65 \pm 11.7$ & $80 \pm 11.7$ & 0.99 \\
\hline With 3 to 4 legs in stall & $12.4 \pm 1.1$ & $12.5 \pm 1.1$ & 0.86 & $35 \pm 2.5$ & $33 \pm 2.5$ & 0.53 \\
\hline Total & $24.0 \pm 1.8$ & $25.2 \pm 1.8$ & 0.89 & $100 \pm 12.8$ & $113 \pm 12.8$ & 0.65 \\
\hline Lying in freestalls & $10.7 \pm 0.3$ & $10.3 \pm 0.3$ & 0.86 & $758 \pm 7.2$ & $741 \pm 7.2$ & 0.13 \\
\hline
\end{tabular}


Table 2. Mean ( \pm SEM) daily frequency and duration of behaviors of cows with either concrete or Animat flooring in front of feed bunk in Experiment $2(n=16)$

\begin{tabular}{|c|c|c|c|c|c|c|}
\hline & \multicolumn{3}{|c|}{ Bout frequency (no./24 h) } & \multicolumn{3}{|c|}{ Total duration $(\min / 24 \mathrm{~h})$} \\
\hline & Concrete & Animat & $P$ & Concrete & Animat & $P$ \\
\hline Total standing & $9.3 \pm 0.7$ & $8.4 \pm 0.7$ & 0.08 & $712 \pm 28.8$ & $650 \pm 28.8$ & 0.02 \\
\hline Eating & $17.5 \pm 1.5$ & $20.6 \pm 1.5$ & $<0.01$ & $289 \pm 15.4$ & $330 \pm 15.3$ & $<0.01$ \\
\hline Without eating & $19.1 \pm 1.8$ & $23.7 \pm 1.8$ & $<0.01$ & $115 \pm 20.5$ & $176 \pm 20.4$ & $<0.01$ \\
\hline Using drinker & $9.8 \pm 1.0$ & $11.0 \pm 1.0$ & 0.10 & & & \\
\hline Standing in alleyways & $5.9 \pm 0.8$ & $5.3 \pm 0.8$ & 0.08 & $19 \pm 2.9$ & $15 \pm 2.9$ & 0.04 \\
\hline Standing in freestalls & & & & & & \\
\hline With front legs in stall & $11.9 \pm 1.2$ & $8.3 \pm 1.2$ & $<0.01$ & $119 \pm 17.1$ & $67 \pm 17.1$ & $<0.01$ \\
\hline With 3 to 4 legs in stall & $12.2 \pm 1.3$ & $7.5 \pm 1.3$ & $<0.01$ & $173 \pm 33.1$ & $65 \pm 33.0$ & $<0.01$ \\
\hline Total & $24.1 \pm 2.5$ & $15.8 \pm 2.5$ & $<0.01$ & $292 \pm 50.2$ & $132 \pm 50.1$ & $<0.01$ \\
\hline Lying in feeding area & $0.4 \pm 0.4$ & $1.6 \pm 0.4$ & $<0.01$ & $53 \pm 53.6$ & $219 \pm 53.5$ & $<0.01$ \\
\hline Lying in freestalls & $8.8 \pm 1.0$ & $6.8 \pm 1.0$ & $<0.01$ & $670 \pm 61.3$ & $566 \pm 61.2$ & 0.27 \\
\hline Lying (total) & $9.2 \pm 0.7$ & $8.5 \pm 0.7$ & 0.12 & $727 \pm 28.9$ & $789 \pm 28.8$ & 0.02 \\
\hline
\end{tabular}

bouts of eating in this position. Cows spent 12 times longer eating with only 2 legs on the flooring surface when using the concrete platform compared with the sawdust. Cows also spent more time $(27 \mathrm{~min} / \mathrm{d})$ standing without eating on the sawdust surface, due to more standing bouts.

There was no difference between treatments in number of visits to the feeder or the freestalls (sawdust vs. concrete: $8.5 \pm 0.39$ vs. $8.1 \pm 0.39$ visits $/ \mathrm{d} ; P=0.86$ ). There were also no differences in either lying or standing behavior in the stalls associated with flooring treatments.

\section{Experiment 2}

There were no significant interactions between type of floor and parity. Cows spent more time standing near the feeder (eating and not eating), and less time standing elsewhere in the pen when the Animat surface was available (Table 2). The frequency of standing bouts was also greater, suggesting that cattle are more likely to change position with Animat in front of the feed bunk. Some animals did lie down in the feeding area, but only on the Animat treatment. Indeed, cows spent significantly more time lying down in the alley in front of the feed bunk during the Animat treatment $(219 \mathrm{~min} /$ d) than during the concrete treatment $(53 \mathrm{~min} / \mathrm{d}$ ). There was no effect of flooring on the use of the drinkers. The flooring treatment also affected the behavior of cows in the other alleyways and freestalls. Cows spent less time standing, both with 2 legs, and 3 or 4 legs, in the freestalls when rubber flooring was in front of the feed bunk. There was a slight reduction in the number of standing bouts in the alleyways associated with the Animat flooring (in between feed bunk and freestalls). There was no effect of the flooring treatment on the time spent lying in the stalls, but bout frequency was greater for Animat. Feed intake did not differ between the 2 flooring types (Animat vs. concrete, $28.0 \pm 0.84$ vs. $27.4 \pm 0.84 \mathrm{~kg} / \mathrm{d} ; P=0.34)$.

\section{DISCUSSION}

Our results show that cows prefer to stand on softer flooring surfaces than concrete when eating, and that having such surfaces near feed bunks may increase the time cows spend in this area. In Experiment 1, cows ate $800 \mathrm{~g} / \mathrm{d}$ more hay when fed from the softer sawdust surface. This increase in feed intake was not replicated in Experiment 2, indicating that the effect of flooring surfaces on feed intake is variable.

Cows in Experiment 1 preferred to use the sawdust flooring compared with the concrete. This preference was apparent in the amount of time spent eating, amount of feed consumed, and time spent standing on the sawdust not eating. Although none of the cows showed a preference for concrete, all spent at least some time standing on concrete, and some cows had no clear preference between the 2 alternatives. These results differ from the overwhelming preferences shown for softer lying surfaces in freestalls, where cows often spend $100 \%$ of their time on the preferred surface (Manninen et al., 2002), but is similar to the preferences shown for specific feed types (Rutter et al., 2004). One possible explanation for this less-than-absolute preference is that cows trade off their preference for standing on the sawdust against their motivation to explore the second feed source (in front of the concrete treatment). Indeed, cows may have selected the most desirable feed from both surfaces, and future studies should compare the quality of feed refusals remaining in each feed source.

The preference of cows for softer surfaces corresponded with longer time spent at or near the feed bunk 
in both Experiments 1 and 2 . Cows spent 27 and $61 \mathrm{~min} /$ $\mathrm{d}$ more standing without eating on the softer surfaces in Experiments 1 and 2, respectively. These results are consistent with previous studies, which found that cows spent more time standing without eating on rubber flooring or slats compared with solid concrete (Stefanowska et al., 2001; Fregonesi et al., 2004). Also consistent with other studies (Stefanowska et al., 2001; Fregonesi et al., 2004), the effect of flooring on eating time was variable. Total eating time was greater on the softer flooring in both experiments, but only statistically more in Experiment 2 . In contrast, the higher intakes on the softer surface were only significant for Experiment 1. Clearly, eating time cannot be directly related to feed intake (Nielsen, 1999) and more work is required to understand this relationship under different conditions.

Lying in the alley in front of the feed bunk is clearly undesirable. Cows in Experiment 2 spent an additional $1.7 \mathrm{~h} / \mathrm{d}$ lying down in front of the feed bunk when provided the Animat flooring. However, the cows in this experiment also lay down in front of the feed bunk when the flooring was concrete, suggesting that the comfort of the freestalls was inadequate. Indeed, multiparous cows in Experiment 2 spent only $547 \mathrm{~min} / \mathrm{d}$ lying in the stalls compared with $750 \mathrm{~min} / \mathrm{d}$ in Experiment 1. In Experiment 1, only 2 cows briefly (less than $1 \mathrm{~min}$ ) lay down on the sawdust flooring surface at the feed bunk and there was no difference in time spent lying down in the stalls associated with treatment. These differences between the 2 experiments likely reflect differences in the comfort in the stalls between experiments, and show the value of studying design features under a range of conditions. Vokey et al. (2001) found an interaction between flooring surfaces and comfort of freestalls: cows housed with rubber flooring and sand-bedded freestalls had better claw and leg health than cows kept on a combination of concrete floors and concrete-based freestalls. These findings highlight the importance of studying the comfort of the entire facility rather than concentrating on just a single component.

In addition to differences in time spent standing and lying near the feed bunk, there was an effect on the number of bouts of standing in both experiments, indicating that cows changed position more often on the softer flooring surface. This finding suggests that the quality of the flooring affects the ease with which the cows move because changing between eating and not eating required that the cows take some steps. This finding is consistent with other studies that have found that cows take longer strides and steps when walking on sand or rubber compared with concrete (Telezhenko and Bergsten, 2005). We also found that the position while eating differed between the sawdust and concrete surfaces in Experiment 1. Cows spent $45 \mathrm{~min} / \mathrm{d}$ less time eating with only 2 legs on the surface for sawdust compared with concrete flooring. This result again indicates that cows prefer to stand on sawdust and that flooring surface affects both time budget measures (e.g., time spent standing without eating) and more subtle postures (e.g., standing position while eating).

The flooring treatments also influenced standing in the freestall. In Experiment 2, cows spent nearly $2.5 \mathrm{~h}$ less time standing in the stalls when they had access to rubber flooring in front of the feed bunk. This reduction in standing time may improve stall cleanliness (Gaworski et al., 2003; Tucker et al., 2005) and reduce competition for lying in stalls when stocking density is high. Earlier studies have reported that cows spent less time standing (Stefanowska et al., 2001) or lying (Fregonesi et al., 2004) in stalls when provided access to a more comfortable flooring surface outside the stall. However, we found no differences in stall use in Experiment 1 . The reasons for the differences in our 2 experiments and, indeed, within the existing literature, are not immediately obvious. The degree to which cows stand in the lying stalls has often been used to assess the degree of comfort in freestalls (Tucker and Weary, 2004). However, our results show that this behavior may reflect the absence of comfortable places for the cows to stand outside of the freestalls.

We caution that our results need further replication before being directly applicable to group-housed cows on commercial dairies. To eliminate the effects of competition in groups that might have masked the effects of the flooring material, the cows were housed individually with ad libitum access to feed. This differs from normal housing conditions in which groups of cows compete for desirable feed. In addition, we used nonlactating cows as subjects; results may have been more pronounced with lactating cows that have more restricted time budgets, higher energy requirements, and are more likely to experience lameness. Indeed, the degree of claw and leg health may influence the response to flooring surfaces. In our experiments, we did not measure lameness, and because alternative flooring surface may be especially important for these at-risk animals, future experiments should examine the relative value of alternative flooring surfaces for lame cows. However, our results indicate that concrete flooring is uncomfortable and alternatives should be provided, especially given the increasing evidence of a link between concrete flooring and development of lameness (e.g., Vokey et al., 2001; Cook, 2003; Somers et al., 2003).

In conclusion, cows clearly preferred nonconcrete flooring surfaces; they were more willing to move, alter feeding position, and spend more time standing without eating on nonconcrete surfaces. Under some conditions, 
such as when freestalls are uncomfortable, softer flooring resulted in an increase in time spent lying down in the alley in front of the feed bunk. Lying down in the alley is undesirable, but uncomfortable flooring should not be used to encourage cows to use inadequate freestalls. Our results show that improving the comfort of flooring surfaces can highlight other areas for improvement within the facility. Finally, it remains unclear which characteristics of alternative flooring surfaces are important for dairy cattle. Sawdust and Animat differ from concrete in a number of ways (e.g., friction, softness), and additional work is required to understand how dairy cows respond to these features. Both preference testing and behavior in nonchoice situations are suitable ways of assessing the properties of flooring surfaces.

\section{ACKNOWLEDGMENTS}

We thank Michelle Nelson, Laura Paton, Marjolaine St-Louis, Wendy King, and Isabelle Blanchet for their help running segments of these experiments. We thank members of the UBC South Campus Research and Teaching Complex, the staff and students of UBC Animal Welfare Program, and the staff of the Lennoxville Dairy Centre for their help and cooperation. We are grateful to Emily Patterson-Kane for her suggestions about Figure 1. This research was supported by a grant from the Dairy Farmers of Canada, the Natural Sciences and Engineering Research Council of Canada through the Industrial Research Chair in Animal Welfare, and by contributions from the Beef Cattle Industry Development Fund, the BC Dairy Foundation, the BC SPCA, the BC Veterinary Medical Association and many other donors listed on our web site at www.agsci.ubc.ca/animalwelfare.

\section{REFERENCES}

Conover, W. J., and R. L. Iman. 1981. Rank transformations as a bridge between parametric and nonparametric statistics. Am. Stat. 35:124-129.

Cook, N. B. 2003. Prevalence of lameness among dairy cattle in Wisconsin as a function of housing type and stall surface. J. Am. Vet. Med. Assoc. 223:1324-1328.

Fregonesi, J. A., C. B. Tucker, D. M. Weary, F. C. Flower, and T. Vittie. 2004. Effect of rubber flooring in front of the feed bunk on the time budgets of dairy cattle. J. Dairy Sci. 87:1203-1207.

Gaworski, M., C. B. Tucker, D. M. Weary, and M. L. Swift. 2003. Effects of stall design on dairy cattle behaviour. Pages 139-146 in 5th Int. Dairy Housing Conf., Fort Worth, TX. K. Janni, ed. Am. Soc. Agric. Eng., St. Joseph, MI.

Jungbluth, T., B. Benz, and H. Wandel. 2003. Soft walking areas in loose housing systems for dairy cows. Pages 171-177 in 5th Int. Dairy Housing Conf., Fort Worth, TX. K. Janni, ed. Am. Soc. Agric. Eng., St. Joseph, MI.

Lopez, H., and M. P. Shipka. 2003. Association of flooring surface to estrous behavior in lactating dairy cows as determined by radiotelemetric estrous detection. Pages 296-302 in 5th Int. Dairy Housing Conf., Fort Worth, TX. K. Janni, ed. Am. Soc. Agric. Eng., St. Joseph, MI.

Lowe, D. E., R. W. J. Steen, and V. E. Beattie. 2001. Preferences of housed finishing beef cattle for different floor types. Anim. Welf. 10:395-404.

Manninen, E., A. M. de Passillé, J. Rushen, M. Norring, and H. Saloniemi. 2002. Preferences of dairy cows kept in unheated buildings for different kind of cubicle flooring. Appl. Anim. Behav. Sci. 75:281-292.

Nielsen, B. L. 1999. On the interpretation of feeding behaviour measures and the use of feeding rate as an indicator of social constraint. Appl. Anim. Behav. Sci. 63:79-91.

Phillips, C. J. C., and I. D. Morris. 2001. The locomotion of dairy cows on floor surfaces with different frictional properties. J. Dairy Sci. 84:623-628.

Phillips, C. J. C., and S. A. Schofield. 1994. The effect of cubicle and straw yard housing of the behaviour, production and hoof health of dairy cows. Anim. Welf. 3:37-44.

Rushen, J., A. M. de Passillé, F. Borderas, C. Tucker, and D. Weary. 2004. Designing better environments for cows to walk and stand. Pages 55-64 in Adv. Dairy Technol. Vol. 16. J. Kennelly, ed. Univ. Alberta, Red Deer, Alberta, Canada.

Rutter, S. M., R. J. Orr, N. H. Yarrow, and R. A. Champion. 2004. Dietary preference of dairy cows grazing ryegrass and white clover. J. Dairy Sci. 87:1317-1324.

SAS Institute. 1999. User's Guide: Statistics. Version 8 ed. SAS Inst., Inc., Cary, NC.

Somers, J. G. C., J., K. Frankena, E. N. Noordhuizen-Stassen, and J. H. M. Metz. 2003. Prevalence of claw disorders in Dutch dairy cows exposed to several floor systems. J. Dairy Sci. 86:2082-2093.

Stefanowska, J., D. Swierstra, C. R. Braam, and M. M. W. B. Hendriks. 2001. Cow behaviour on a new grooved floor in comparison with a slatted floor, taking claw health and floor properties into account. Appl. Anim. Behav. Sci. 71:87-103.

Telezhenko, E., and C. Bergsten. 2005. Influence of floor type on the locomotion of dairy cows. Appl. Anim. Behav. Sci. 93:183-197.

Tucker, C. B., and D. M. Weary. 2004. Bedding on geotextile mattresses: How much is needed to improve cow comfort? J. Dairy Sci. 87:2889-2895.

Tucker, C. B., D. M. Weary, and D. Fraser. 2005. Influence of neckrail placement on free-stall preference, use, and cleanliness. J. Dairy Sci. 88:2730-2737.

USDA. 2002. Part I: Reference of dairy health and management in the United States. USDA:APHIS:VS, CEAH, National Animal Health Monitoring System, Fort Collins, CO.

van der Tol, P. P. J., J. H. M. Metz, E. N. Noordhuizen-Stassen, W. Back, C. R. Braam, and W. A. Weijs. 2005. Frictional forces required for unrestrained locomotion in dairy cattle. J. Dairy Sci. 88:615-624.

Vokey, F. J., C. L. Guard, H. N. Erb, and D. M. Galton. 2001. Effects of alley and stall surfaces on indices of claw and leg health in dairy cattle housed in a free-stall barn. J. Dairy Sci. 84:2686-2699. 